\title{
PSEUDO ANISOTROPY INDUCED BY MEMBRANE COMPLIANCE IN CEMENTED GRANULAR SOILS
}

\author{
M. A. ISMAIL ${ }^{\text {i) }}$ and M. F. RAndolPH ${ }^{\mathrm{ii}}$
}

\begin{abstract}
The pore pressure response of elastic stiff materials during undrained loading is a function of the volumetric stiffness of the skeleton and stiffness anisotropy. This paper presents experimental results examining the influence of these factors on the pore pressure response in conventional triaxial tests. In order to explore fully the undrained behaviour, the total stress path (TSP) was rotated to cover $180^{\circ}$ in the triaxial plane. It was found that a unique linear relationship exists between the pore pressure coefficient $(\Delta u / \Delta q)$ and the direction of the TSP $(\Delta p / \Delta q)$ with a slope equivalent to the Skempton pore pressure parameter $(B)$, which may be below unity for stiff materials. The intercept of this linear relationship reflects the effect of the material's anisotropy. It has been demonstrated that a pseudo anisotropy of repeatable and consistent nature was induced by membrane compliance in granular cemented soils. The results have shown that, unless eliminated or taken into account, the membrane compliance may lead to erroneous interpretation of pore pressure response. The paper discusses the implications of this finding.
\end{abstract}

Key words: cemented sand, membrane compliance, pore pressure parameters, stiffness anisotropy, triaxial test (IGC: D6)

\section{INTRODUCTION}

In geomaterials where the volumetric compressibility of the pore fluid is much smaller than that of the soil skeleton, a vertical effective stress path (ESP) (constant mean effective stress path, $d p^{\prime}=0$ ) is obtained when a sample is sheared undrained within its elastic range in a conventional triaxial test (CIU) (Fig. 1). However, there are two cases that may lead to deviation of the ESP from vertical:

i) when the compressibility of the skeleton decreases in relation to that of the pore fluid;

ii) when the material possesses stiffness anisotropy.

The symptom of a low skeleton compressibility in a CIU test is an inclination of the ESP towards the total stress path (TSP) (sample a in Fig. 1). On the other hand, stiffness anisotropy may shift the ESP towards or away from the TSP, depending on the ratio of the horizontal to vertical stiffness (Atkinson, 1975; Graham and Houlsby, 1983; Graham and Shields, 1985). Inclination of the ESP to the right indicates higher vertical than horizontal stiffness (sample b in Fig. 1) and vice versa (sample c). Graham and Houlsby (1983) showed that a significant degree of anisotropy may lead to only a small inclination of the ESP. This observation reflects the necessity to examine and quantify the degree of anisotropy accurately.

For elastic stiff materials, Cuccovillo and Coop (1998)

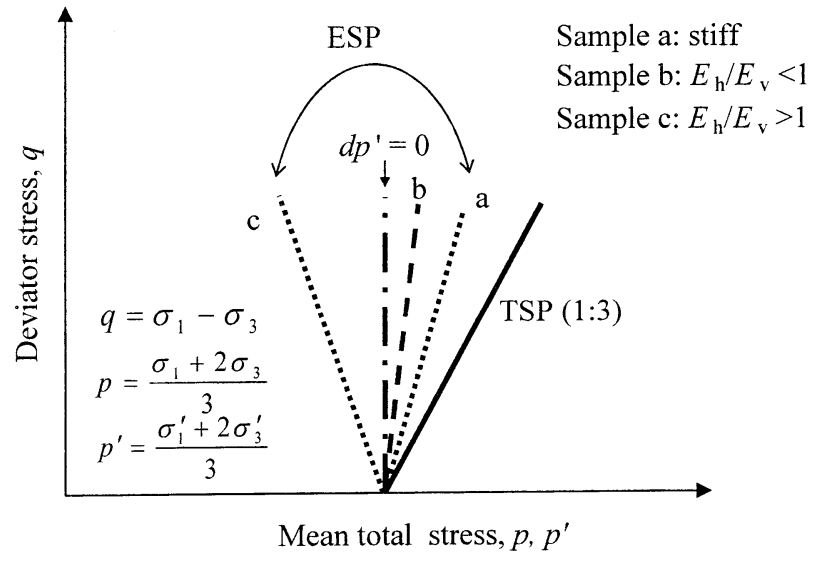

Fig. 1. Schematic showing the influence of volumetric stiffness and anisotropy on the orientation of the ESP during a conventional CIU test

recommended that, before attributing the inclination of the ESP to stiffness anisotropy, the relative volumetric compressibility between the pore fluid and the geomaterial should be investigated first. Their measurements on naturally cemented sandstone indicated that the cementation increased the bulk modulus to three times more than that of water, and this led to an inclination of the ESP ( $\Delta p^{\prime} / \Delta q \approx 0.22$ compared to 0.33 for the TSP) as shown

i) Lecturer, UWA, Centre for Offshore Foundation Systems, The University of Western Australia, 6009, Crawley, WA, Australia (mismail@ cyllene.uwa.edu.au).

ii) Professor, ditto.

The manuscript for this paper was received for review on November 14, 2003; approved on January 18, 2005.

Written discussions on this paper should be submitted before January 1, 2006 to the Japanese Geotechnical Society, 4-38-2, Sengoku, Bunkyoku, Tokyo 112-0011, Japan. Upon request the closing date may be extended one month. 


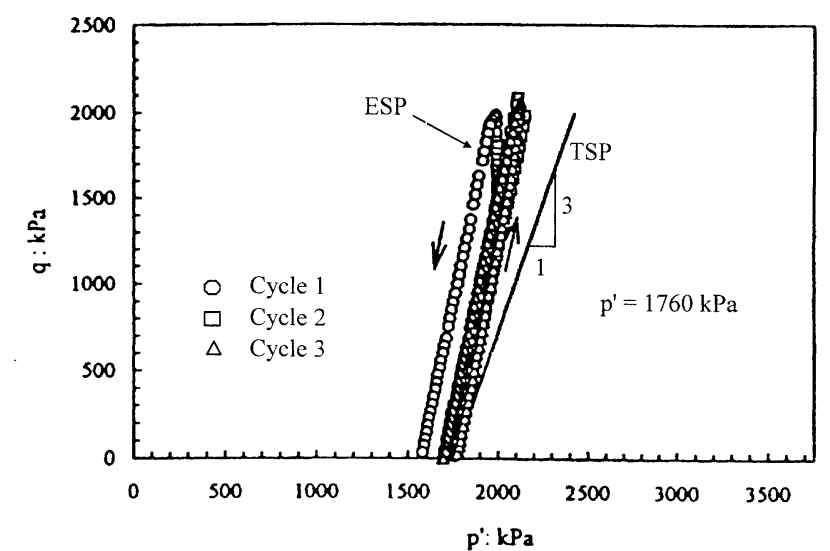

Fig. 2. Effective stress path (ESP) in undrained shearing of silica sandstone (after Cuccovillo and Coop, 1998)

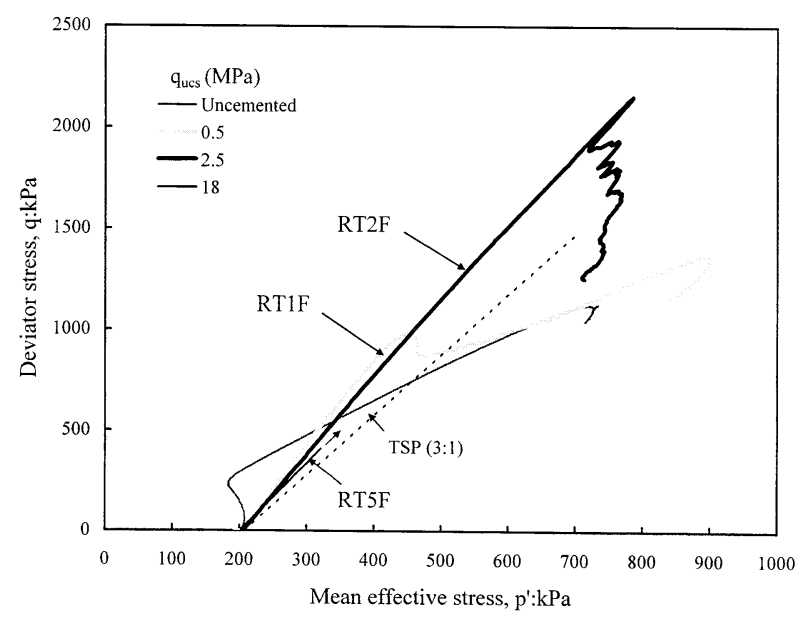

Fig. 3. Initial gradient of the effective stress path of RT sand in CIU test for different levels of cementation

in Fig. 2.

A comprehensive investigation into the strength and deformation behaviour of calcareous soils cemented artificially with calcite has been undertaken at the University of Western Australia since the late 1990s. As shown in Fig. 3, it was found that the ESP is persistently inclined towards the TSP over a wide range of level of cementation (unconfined compressive strength, $q_{\text {ucs }}=0.5 \mathrm{MPa}$ to $18 \mathrm{MPa}$ ). This finding raised the question of whether anisotropy or the cementation-acquired stiffness alone could be responsible for that response. Surprisingly, it has been found that a third factor, membrane compliance, was largely responsible for the increasing inclination of the ESP.

To separate the effects of volumetric compressibility, intrinsic anisotropy and pseudo anisotropy due to membrane compliance, the experimental program was extended to include samples of artificial sandstone, isotropic acrylic and intrinsically anisotropic wood. A series of undrained triaxial compression test was undertaken, varying the direction of the TSP to cover $180^{\circ}$ in the shear plane. The paper analyses the observed pore

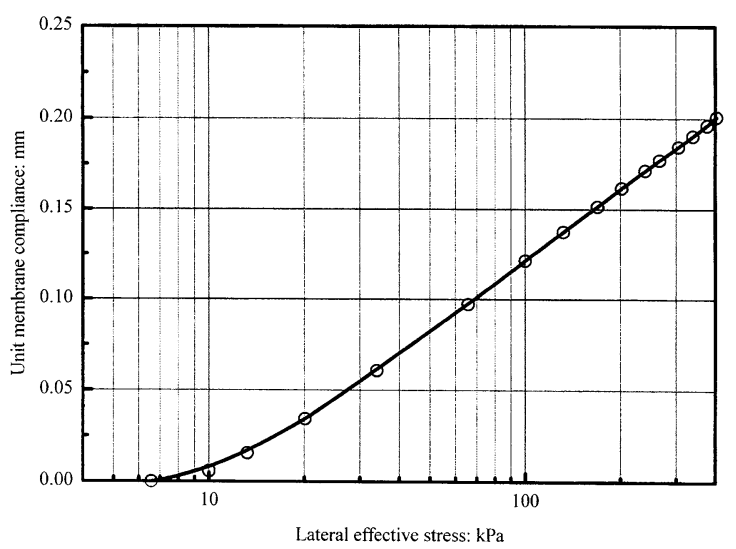

Fig. 4. Typical relationship between unit membrane compliance and lateral effective stress (after Nicholson et al., 1993)

pressure response of the different samples and discusses the implications of the findings.

\section{MEMBRANE COMPLIANCE}

Although an intensive experimental database has been generated regarding the influence of membrane compliance on pore pressure response of granular uncemented materials (e.g., Frydman et al., 1973; Raju and Sadasivan, 1974; Nicholson et al., 1993; Sivathayalan and Vaid, 1998), very little has been compiled in the case of cemented granular materials. Previous research has shown that the magnitude of volume change induced by membrane compliance is most affected by particle size and gradation, and all other factors are deemed secondary (Nicholson et al., 1993). The effect of membrane compliance is negligible only for soils with average particle sizes below $0.1 \mathrm{~mm}-0.2 \mathrm{~mm}$ (Lade and Hernandez, 1977; Frydman et al., 1973). Accordingly, in the case of cemented sand of larger particle size, where only small proportion of a cementing agent is added, or where the cement does not change soil fabric significantly, membrane-induced volume change should be expected.

Cuccovillo and Coop (1998) reported a significant variation of the pore pressure response during a $B$-value test due to variation of the lateral effective stress $\left(\sigma_{3}^{\prime}\right)$. For example, their measured $B$ value changed from 0.99 to a much lower true value of 0.45 at $\sigma_{3}^{\prime}$ of 60 and $460 \mathrm{kPa}$, respectively. They attributed the variation in the $B$ value to the effect of the membrane compliance, which should have been reduced at higher $\sigma_{3}^{\prime}$.

Experience with granular uncemented materials has shown that the volume change due to membrane compliance is a repeatable function of $\sigma_{3}^{\prime}$ for particular sample and membrane conditions (Nicholson et al., 1993). A typical relationship between the unit membrane compliance $\left(\delta v_{\mathrm{m}}\right)$ and $\sigma_{3}^{\prime}$ is shown in Fig. 4 , where $\delta v_{\mathrm{m}}=$ volume change due to membrane compliance normalised by the membrane surface area (Frydman et al., 1973). It turns out from this relationship that the membrane compliance varies eventually linearly with logarithm $\sigma_{3}^{\prime}$. 
As will be shown later, this relationship is also valid for cemented calcareous sand, and should be taken into account.

\section{COEFFICIENT OF PORE PRESSURE $\left(A^{*}=\Delta u / \Delta q\right)$}

For a cross-anisotropic elastic material, the compliance matrix relating strain and stress increments may be written as (Atkinson and Sallfors, 1991):

$$
\left\{\begin{array}{l}
d \varepsilon_{\mathrm{v}} \\
d \varepsilon_{\mathrm{q}}
\end{array}\right\}=\left[\begin{array}{cc}
\frac{1}{K} & \frac{1}{J} \\
\frac{1}{J} & \frac{1}{3 G}
\end{array}\right]\left\{\begin{array}{l}
d p^{\prime} \\
d q
\end{array}\right\}
$$

where $K, G$ are the bulk and shear moduli, respectively; $J$ is a modulus coupling the change in volumetric strain $\left(d \varepsilon_{\mathrm{v}}\right)$ to change in the deviator stress $(d q)$ and vice versa. For a sample tested in the triaxial apparatus,

$$
\begin{aligned}
& p^{\prime}=\frac{\sigma_{1}^{\prime}+2 \sigma_{3}^{\prime}}{3} ; \quad q=\sigma_{1}^{\prime}-\sigma_{3}^{\prime} ; \quad d \varepsilon_{\mathrm{v}}=d \varepsilon_{1}+2 d \varepsilon_{3} ; \\
& d \varepsilon_{\mathrm{q}}=(2 / 3)\left(d \varepsilon_{1}-d \varepsilon_{3}\right)
\end{aligned}
$$

Let us now impose an undrained stress probe $\Delta p / \Delta q=$ constant on a triaxial sample consolidated to $p^{\prime}$. The compatibility condition (Bishop, 1973) entails that the summation of volume change experienced by the skeleton of the sample should equal the summation of volume change experienced by the different components (i.e. soil grains and pore fluids). If the sample is fully saturated and the pores are filled with water, this condition can be expressed mathematically as

$$
\begin{aligned}
& {\left[\Delta V_{(\Delta \mathrm{u})}+\Delta V_{(\Delta \mathrm{p}-\Delta \mathrm{u})}+\Delta V_{(\Delta \mathrm{q})}\right]_{\text {skeleton }}} \\
& \quad=\left[\Delta V_{(\Delta \mathrm{u})}+\Delta V_{(\Delta \mathrm{p}-\Delta \mathrm{u})}\right]_{\text {solid }}+\left[\Delta V_{(\Delta \mathrm{u})}\right]_{\text {water }}
\end{aligned}
$$

The subscripts (inside parentheses) of this equation refer to the stress agent causing the volume change. To account for the membrane compliance, Lade and Hernandez (1977) defined the membrane flexibility $f_{\mathrm{m}}=\Delta V_{\mathrm{m}} / \Delta \sigma_{3}^{\prime}$, where $\Delta V_{\mathrm{m}}$ is the volume change induced by the membrane deformation towards (or away from) the skeleton due to change of lateral effective stress of $\Delta \sigma_{3}^{\prime}$. Accounting for the membrane compliance in Eq. (2) yields

$$
\begin{gathered}
{\left[\Delta V_{(\Delta \mathrm{u})}+\Delta V_{(\Delta \mathrm{p}-\Delta \mathrm{u})}+\Delta V_{(\Delta \mathrm{q})}\right]_{\text {skeleton }}+\Delta V_{\mathrm{m}}} \\
\quad=\left[\Delta V_{(\Delta \mathrm{u})}+\Delta V_{(\Delta \mathrm{p}-\Delta \mathrm{u})}\right]_{\text {solid }}+\left[\Delta V_{(\Delta \mathrm{u})}\right]_{\text {water }}
\end{gathered}
$$

Substituting for the different components of volume change in Eq. (3), we get

$$
\begin{aligned}
& \left(C_{\mathrm{g}}\right)(\Delta u)\left(V_{\mathrm{o}}\right)+(C)(\Delta p-\Delta u)\left(V_{\mathrm{o}}\right) \\
& \quad+(1 / J)(\Delta q)\left(V_{\mathrm{o}}\right)+\left(f_{\mathrm{m}}\right) \Delta \sigma_{3}^{\prime} \\
& \quad=\left(C_{\mathrm{g}}\right)(\Delta u)(1-n)\left(V_{\mathrm{o}}\right)+\left(V_{\mathrm{o}}\right)\left(C_{\mathrm{g}}\right)(\Delta p-\Delta u) \\
& \quad+(n)\left(V_{\mathrm{o}}\right)\left(C_{\mathrm{w}}\right)(\Delta u)
\end{aligned}
$$

where $C_{\mathrm{g}}$ is the compressibility of the grains, $C$ is the volumetric compressibility of the skeleton $(C=1 / K), C_{\mathrm{w}}$ is the compressibility of water $\approx 5 \times 10^{-7} \mathrm{kPa}^{-1}$, and $n$ is the porosity. Solving Eq. (4) for $\Delta u$ yields:

$$
\begin{aligned}
\Delta u= & B(\Delta p)+\left(\frac{B}{C-C_{\mathrm{g}}+f_{\mathrm{m}} / V_{\mathrm{o}}}\right)\left(\frac{\Delta q}{J}\right) \\
& -\left(\frac{B}{C-C_{\mathrm{g}}+f_{\mathrm{m}} / V_{\mathrm{o}}}\right)\left(\frac{\Delta q f_{\mathrm{m}}}{3 V_{\mathrm{o}}}\right)
\end{aligned}
$$

and

$$
B=\left(\frac{\Delta u}{\Delta p}\right)_{\mathrm{dq}=0}=\frac{C_{\mathrm{g}}-C-\left(f_{\mathrm{m}} / V_{\mathrm{o}}\right)}{C_{\mathrm{g}}(1+n)-n C_{\mathrm{w}}-C-\left(f_{\mathrm{m}} / V_{\mathrm{o}}\right)}
$$

Equation (5) is similar to the one given by Baldi and Nova (1984) for elasto-plastic materials. If the membrane flexibility is neglected, Eq. (6) reduces to (Bishop, 1973):

$$
B=\left(\frac{\Delta u}{\Delta p}\right)_{\mathrm{dq}=0}=\frac{1}{1+n \frac{C_{\mathrm{w}}-C_{\mathrm{g}}}{C-C_{\mathrm{g}}}}
$$

Dividing by $\Delta q$, Eq. (5) may be rewritten as

$$
\begin{aligned}
A^{*}= & \frac{\Delta u}{\Delta q}=B \frac{\Delta p}{\Delta q}+\left(\frac{B}{C-C_{\mathrm{g}}+f_{\mathrm{m}} / V_{\mathrm{o}}}\right)\left(\frac{1}{J}\right) \\
& -\left(\frac{B}{C-C_{\mathrm{g}}+f_{\mathrm{m}} / V_{\mathrm{o}}}\right)\left(\frac{f_{\mathrm{m}}}{3 V_{\mathrm{o}}}\right)
\end{aligned}
$$

The second and third terms of the right hand side of Eq. (8) are linked to anisotropy and membrane flexibility, respectively. Therefore, in $(\Delta u / \Delta q)-(\Delta p / \Delta q)$ space, Eq. (8) plots as a straight line with gradient of $B$ and intercept reflecting either the intrinsic anisotropy or the membrane flexibility, or a combination of both.

If the material is isotropic with no membrane compliance, Eq. (8) reduces to the familiar relationship of Skempton (1954) (here in terms of $\Delta p$ and $\Delta q$ ). Furthermore, if $C$ is very large compared with $C_{\mathrm{w}}, B \approx$ unity and in a conventional CIU test, $A^{*} \approx 1 / 3$ (i.e. $A^{*}=$ the familiar Skempton pore pressure parameter $A$ ).

\section{MATERIALS TESTED AND SAMPLE PREPARATION}

To test the validity of Eq. (8) and examine the influence of volumetric compressibility, intrinsic anisotropy and membrane compliance on the response of pore pressure during undrained loading, triaxial samples were prepared from cemented sands, acrylic and wood, each possessing certain characteristics.

For the cemented samples, silica sand (or Si sand) and one offshore calcareous sand (Rottnest or RT sand) were cemented artificially using calcite by means of the CIPS process (Calcite In situ Precipitation System; Ismail et al., 2002). In the CIPS process, a sample is first prepared dry by pluviation into a mould lined with a latex membrane (Fig. 5). The density of the sample is controlled by gently tapping the wall of the mould until a certain height is reached, using a special density adapter (see Fig. 5). While in the mould, the sample is subjected to a vertical pressure of $50 \mathrm{kPa}$, using dead weight. De-aired water is flushed through the sample from bottom to top at pressure of about $20 \mathrm{kPa}$, followed by the CIPS solution. The sample is left to cure for overnight, before applying 


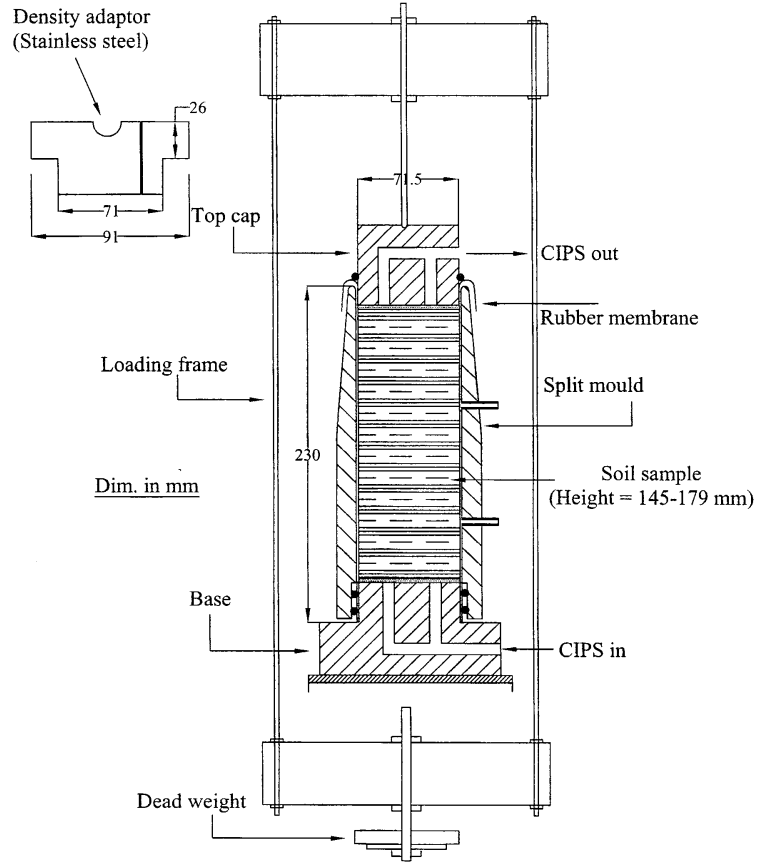

Fig. 5. Setup for cementing sand using CIPS (after Ismail et al., 2000)

Table 1. Physical properties of tested soils

\begin{tabular}{lcccccc}
\hline Soil & $\begin{array}{c}D_{10} \\
(\mathrm{~mm})\end{array}$ & $\begin{array}{c}D_{50} \\
(\mathrm{~mm})\end{array}$ & $\%$ Fines & $e_{\max }$ & $e_{\min }$ & $\mathrm{CaCO}_{3}(\%)$ \\
\hline $\mathrm{RT}$ & 0.170 & 0.30 & 0.80 & 1.231 & 0.824 & 85 \\
$\mathrm{Si}$ & 0.320 & 0.47 & 0.30 & 0.755 & 0.520 & 0 \\
\hline
\end{tabular}

the second flush. The process is repeated until the required number of flushes is applied. 24 hours after the final flush, the sample is taken out for further testing. Uniformity of the cemented sample produced by this method was confirmed by measuring the shear wave velocity along the diameter of the sample at different points across the sample length with spacing of about $30 \mathrm{~mm}$; variation of the shear wave velocity of only less than $1 \%$ was detected.

The characteristics of $\mathrm{Si}$ and $\mathrm{RT}$ sands are listed in Table 1 and the gradation curves are shown in Fig. 6, indicating that both sands are of medium size, with $D_{50}$ of $0.3 \mathrm{~mm}$ and $0.47 \mathrm{~mm}$, respectively.

Further details on these soils, the sample preparation technique and details on the cementing agent may be found in Ismail et al. (2002). In the case of the RT sand, several samples were prepared to different levels of cementation as shown in Table 2. Only one sample was prepared from the silica sand with 10 flushes, and designated here as Si10F.

In addition, a prismatic sample was made from acrylic, which was deemed an appropriate medium for this study to control the compressibility and ensure stiffness isotropy. The acrylic sample was square with dimensions $43 \times 43 \mathrm{~mm}$ in section and $85 \mathrm{~mm}$ in height. The sample was cut from a block of acrylic to the required size and

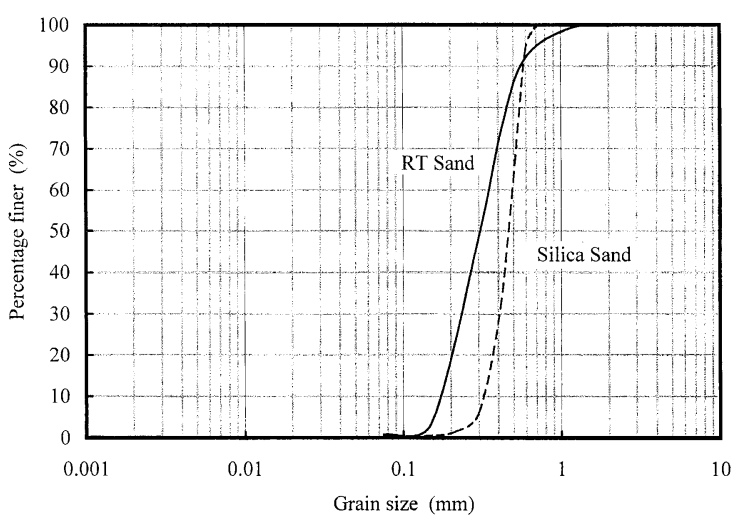

Fig. 6. Grain size distribution curves of $\mathrm{Si}$ and $\mathrm{RT}$ sands before cementation

Table 2. Pre-testing conditions for tested samples

\begin{tabular}{|c|c|c|c|c|c|}
\hline Sample & Material & $\begin{array}{c}\text { Dry density } \\
\left(\mathrm{Mg} / \mathrm{m}^{3}\right)\end{array}$ & $\begin{array}{l}\text { Porosity } \\
\quad(n)\end{array}$ & Dimensions & $q_{\mathrm{ucs}}(\mathrm{MPa})$ \\
\hline $\mathrm{RT}_{1 \mathrm{~F}}{ }^{*}$ & $\begin{array}{l}\text { Rottnest } \\
\text { sand }\end{array}$ & 1.40 & 0.481 & $\begin{array}{c}\text { Cylinder } \\
71.5 \times 166\end{array}$ & 0.5 \\
\hline RT2F & $\begin{array}{l}\text { Rottnest } \\
\text { sand }\end{array}$ & 1.46 & 0.459 & $\begin{array}{c}\text { Cylinder } \\
71.5 \times 166\end{array}$ & 2.5 \\
\hline RT3F & $\begin{array}{l}\text { Rottnest } \\
\text { sand }\end{array}$ & 1.54 & 0.431 & $\begin{array}{c}\text { Cylinder } \\
71.5 \times 166\end{array}$ & 5 \\
\hline RT5F & $\begin{array}{l}\text { Rottnest } \\
\text { sand }\end{array}$ & 1.66 & 0.385 & $\begin{array}{l}\text { Cylinder } \\
71.5 \times 166\end{array}$ & 18 \\
\hline Sil0F & Silica sand & 2.02 & 0.236 & $\begin{array}{l}\text { Cylinder } \\
72 \times 141\end{array}$ & $\approx 100$ \\
\hline Acrylic & Acrylic & 0.74 & 0.346 & $\begin{array}{c}\text { Prism } \\
43 \times 43 \times 85\end{array}$ & 84 \\
\hline Wood & Pinewood & 0.42 & $\mathrm{~N} / \mathrm{A}$ & $\begin{array}{c}\text { Cylinder } \\
71.5 \times 150\end{array}$ & $39^{\mathrm{a})}-19.6^{\mathrm{b})}$ \\
\hline
\end{tabular}

*: $1 \mathrm{~F}, 2 \mathrm{~F}, 3 \mathrm{~F}$, etc. refer to the number of CIPS flushes with 24 hours in between each successive flush.

a), b): Parallel and perpendicular to grains, respectively.

then drilled to achieve a pattern of interconnected, 49 vertical channels and 196 horizontal channels, each of $3 \mathrm{~mm}$ width and the spacing between each two adjacent channels is $6 \mathrm{~mm}$ centre-to-centre. The four long sides of the prism were covered by four acrylic plates of $1.5 \mathrm{~mm}$ thickness to prevent membrane penetration into the horizontal channels during pressure application (Fig. 7).

To examine the influence of intrinsic anisotropy, a wooden cylindrical sample of $72 \mathrm{~mm}$ diameter and $150 \mathrm{~mm}$ height was prepared from Pine. The Pine was selected because it fulfils the requirement of being soft (low bulk modulus compared with water) with high degree of anisotropy as will be shown later. Table 2 lists the conditions and properties of each sample.

\section{TESTING PROGRAM}

A series of undrained triaxial compression test was performed with variation of the direction of the TSP after isotropic consolidation to $p^{\prime}=500 \mathrm{kPa}$ for samples RT5F, Si10F, Acrylic and Pinewood, covering $180^{\circ}$, as shown in Fig. 8. The deviator component of stress was 


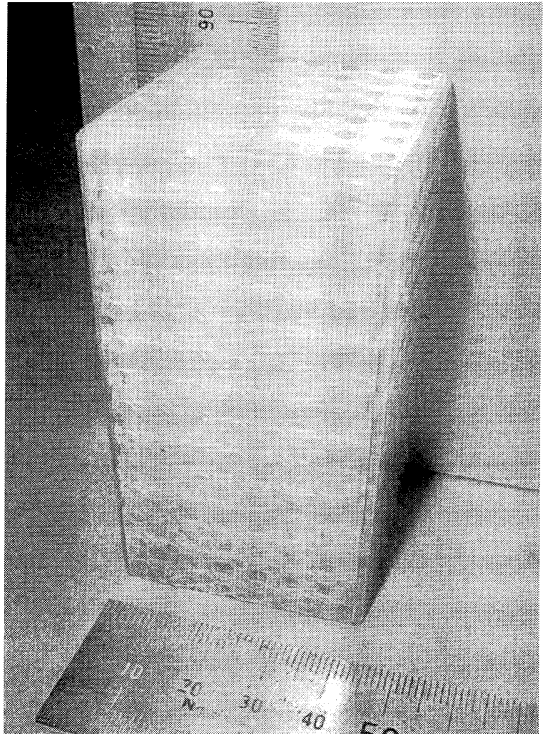

Fig. 7. Photograph of the acrylic sample showing pattern of artificial holes

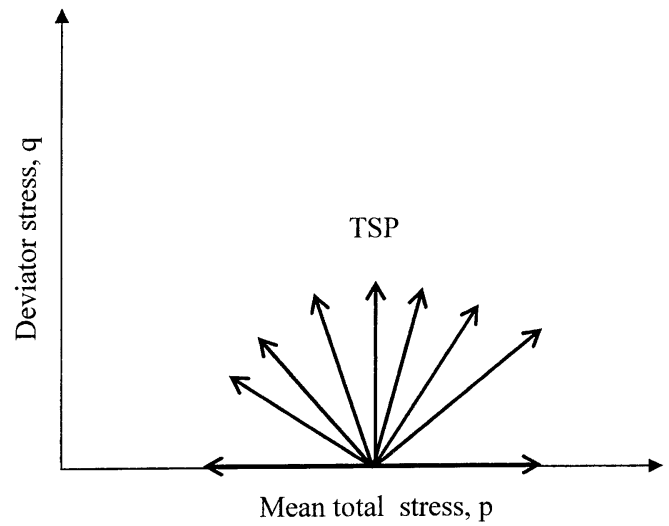

Fig. 8. Probes of total stress path (TSP) during undrained shearing within the elastic range

applied continuously at a vertical displacement rate of $0.05 \mathrm{~mm} / \mathrm{min}$, while adjusting the cell pressure to achieve the required orientation of the TSP. The selected rate of loading was believed to be slow enough for the pore pressure to equalise inside each sample. In the case of the Pinewood sample, this rate was also deemed to be fast enough to avoid the influence of creep. The axial and radial deformations during both isotropic compression and shearing were measured using internal submersible LVDTs (Cuccovillo and Coop, 1998) with a 16-bit data acquisition system capable of resolving the deformation down to 0.152 and 0.077 microns for the axial and radial deformations, respectively. As it was crucial to ensure that the loading remains within the elastic zone of each material (i.e., strains less than $10^{-5}$ ), several cycles of loading-unloading were carried out for each sample and the stress strain curve was analyzed to ensure full recovery of all strains during complete unloading. The length of the loading probe $\left(\Delta q^{2}+\Delta p^{2}\right)^{1 / 2}$ was maintained constant for all samples at $300 \mathrm{kPa}$. All tested samples

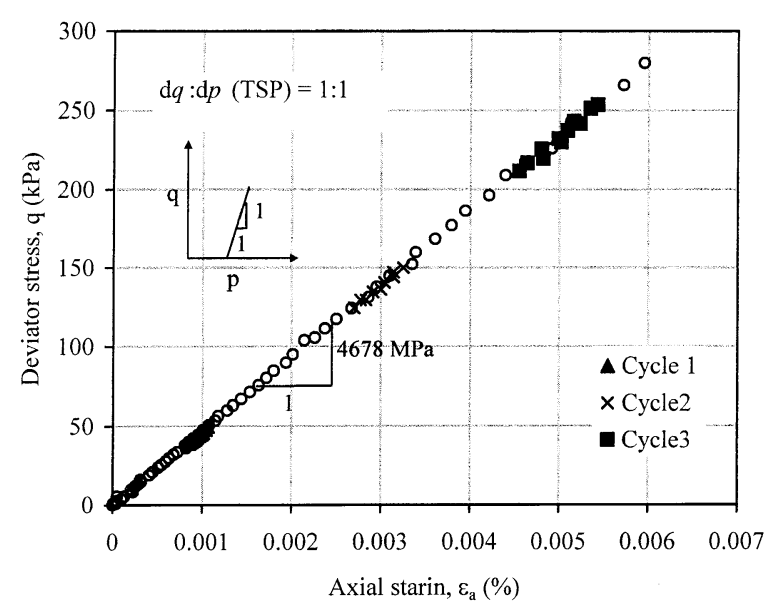

Fig. 9(a). Stress-strain curve showing recoverable strains during load-unload cycles for RT5F sample

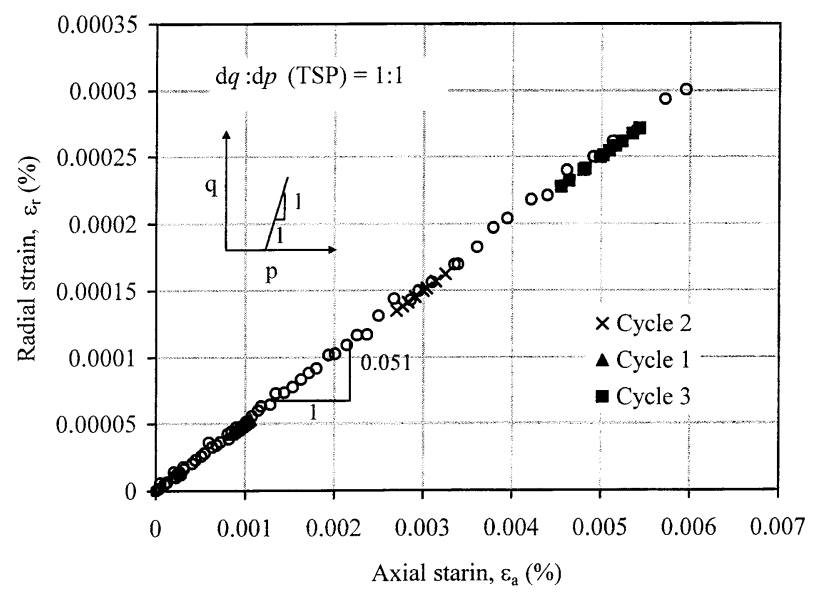

Fig. 9(b). Radial strain versus axial strain during loading the RT5F sample along the line $d q / d p=1$

showed full recovery of strains during unloading and no signs of hysteresis were detected. A typical stress-strain curve is shown for the Sil0F sample in Fig. 9.

To ensure full saturation of tested samples, carbon dioxide was flushed slowly from bottom to top via the back-pressure line over a period of 30 minutes at effective stress of $10 \mathrm{kPa}$. De-aired water was then flushed under $25 \mathrm{kPa}$ for another 30 minutes to dissolve the $\mathrm{CO}_{2}$. Full saturation was further ensured by ramping both the cell and back pressures up to 1030 and $1000 \mathrm{kPa}$, respectively.

The pore pressure parameter, $B$, reduces progressively below unity with increase in the skeleton stiffness of saturated samples. Therefore, a special criterion is required to ensure full saturation. To this end, Wissa (1969) suggested that saturation is considered complete when the $B$ value does not change upon applying different increments of cell pressure. In other words, saturation is inferred when the plot of $\Delta u$ versus $\Delta p$ gives a straight line. This method was used in this study as will be shown later. 


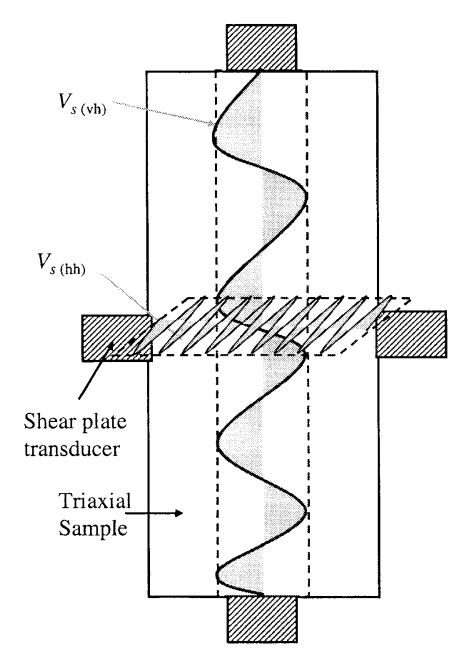

Fig. 10. Schematic showing wave directions and polarisation during measurement of $G_{\mathrm{o}(\mathrm{hh})}$ and $G_{\mathrm{o}(\mathrm{hv})}$

\section{Measurements of Stiffness}

Equation (1) indicates that the most direct way to detect the anisotropy of a triaxial sample is to calculate $J$ from the volume change generated during a drained stress probe of $d p^{\prime}=0$, i.e., $J=\left(d q / d \varepsilon_{\mathrm{v}}\right)_{\mathrm{dp}^{\prime}=0}$. To calculate $J$ independently of the membrane compliance, $d \varepsilon_{\mathrm{v}}$ must be calculated indirectly from the relationship $d \varepsilon_{\mathrm{v}}=d \varepsilon_{1}+2 d \varepsilon_{3}$, which is valid, equally for isotropic and anisotropic samples. This was carried out using the LVDT system described above. The stiffness anisotropy is defined herein as the ratio of Young's moduli $\left(E_{\mathrm{h}} / E_{\mathrm{v}}\right)$ (Graham and Houlsby, 1983). Both $G_{\mathrm{hh}}$ and $G_{\mathrm{vh}}$ were measured directly using shear-plate type transducers (Ismail et al., 2005). This was achieved by incorporating a pair of transducers into the platens of the triaxial machine, so that a wave can be generated in the vertical direction with horizontal polarization [for measuring $\left.V_{\mathrm{s}(\mathrm{vh})}\right]$. Another pair was fixed laterally to each sample through two sleeves protruding out of the rubber membrane. This type of connection is similar to the mid-height pore pressure socket described by Hight (1982), except that it is here a part of the latex membrane with no need for a separate rubber grommet. The diametrically opposite shear transducers were aligned so that particles of the tested sample oscillate horizontally, thereby measuring $V_{\mathrm{s}(\mathrm{hh})}$. Figure 10 shows the wave propagating from the arrangements discussed above, and Fig. 11 shows typical traces received for the RT5F sample. The measured $G_{\mathrm{o}}$ values for all tested samples are listed in Table 3.

\section{Grain Compressibility $\left(C_{g}\right)$ of Silica Sand, $R T$ Sand and Acrylic Samples}

In this study, the compressibility of the grains for the silica sand used in preparing the Si10F sample was taken as $C_{\mathrm{g}}=0.265 \times 10^{-7} \mathrm{kPa}^{-1}$ (Bridgman, 1925). This was determined experimentally for a flawless, solid crystal of quartz subjected to elevated hydrostatic pressure. The compressibility was calculated by accurate measurement

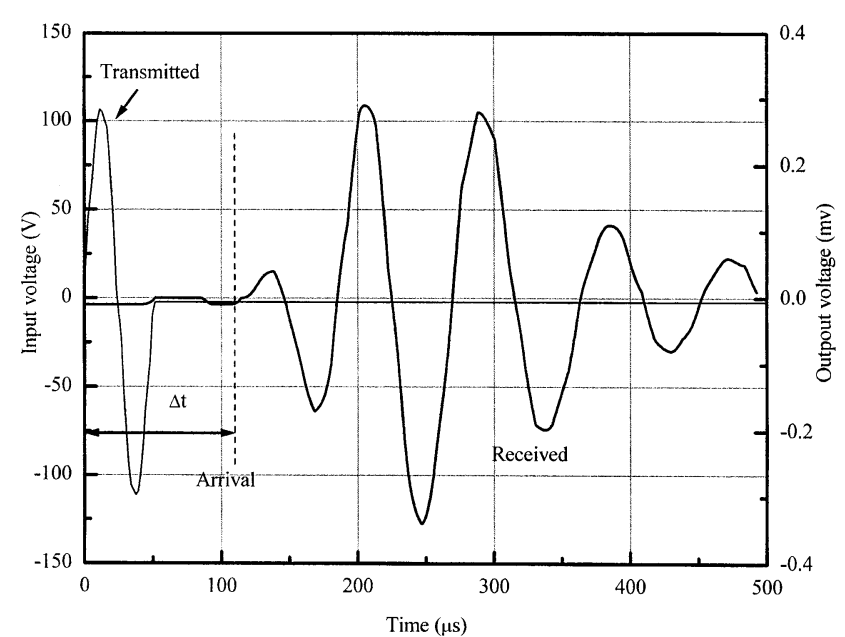

Fig. 11. Traces of transmitted and received signals obtained for the RT5F sample

Table 3. Measured elastic parameters of tested materials

\begin{tabular}{lrrcccc}
\hline Sample & $\begin{array}{r}G_{\mathrm{o}(\mathrm{vh})} \\
(\mathrm{MPa})\end{array}$ & $\begin{array}{r}G_{\mathrm{o}(\mathrm{hh})} \\
(\mathrm{MPa})\end{array}$ & $G_{\mathrm{o}(\mathrm{hh})} / G_{\mathrm{o}(\mathrm{hv})}$ & $v_{\mathrm{vh}}^{\mathrm{a})}$ & $v_{\mathrm{hh}}^{\mathrm{b})}$ & $\begin{array}{c}K \\
(\mathrm{MPa})^{*}\end{array}$ \\
\hline RT5F & 3748 & 3603 & 0.961 & 0.2 & 0.19 & 6498 \\
Si10F & 11402 & 11372 & 0.997 & 0.17 & 0.18 & 13110 \\
Acrylic & 683 & 675 & 0.988 & 0.41 & 0.40 & 2650 \\
Wood & 6462 & 425 & 0.066 & 0.45 & $0.33^{* *}$ & 1290 \\
\hline
\end{tabular}

*Determined as the slope of the $p^{\prime}-\varepsilon_{\mathrm{v}}$ curve, with $\varepsilon_{\mathrm{v}}=\varepsilon_{1}+2 \varepsilon_{3}$.

**The vertical axis was considered as the axis of symmetry for the wood sample.

a) $\quad v_{\mathrm{vh}}$ is the negative ratio between vertical strain and lateral strain due to a unit stress in the horizontal direction. $v_{\mathrm{vh}}$ was computed from the measured $E_{(\mathrm{vh})}$ and $G_{\mathrm{o}(\mathrm{vh})}$ as follows: $v_{\mathrm{vh}}=\left[E_{(\mathrm{vh})} / 2 G_{\mathrm{o}(\mathrm{vh})}-1\right]$.

b) $v_{\mathrm{hh}}$ is the negative ratio between lateral strain in any azimuthal direction and the lateral strain in a perpendicular direction due to a unit stress in that perpendicular direction. $v_{\mathrm{hh}}$ was computed from the measured $E_{(\mathrm{hh})}$ and $G_{\mathrm{o}(\mathrm{hh})}$ as follows: $v_{\mathrm{hh}}=\left[E_{(\mathrm{hh})} / 2 G_{\mathrm{o}(\mathrm{hh})}-1\right]$.

of the crystal lengths after pressure application. The silica sand used here has more than $90 \%$ quartz, and hence the value determined by Bridgman (1925) was deemed applicable. Similarly, a value of $C_{\mathrm{g}}=0.136 \times 10^{-7} \mathrm{kPa}^{-1}$ was measured for calcite crystals (Bridgman, 1925), and this was used here for the RT5F sample, assuming that the mineral composition is the same as for calcite.

The compressibility $\left(C_{\mathrm{g}}\right)$ of the acrylic material was determined indirectly by measuring both Young's modulus $(E)$ and Poisson's ratio $(v)$ in unconfined compressive strength of a solid prism of acrylic instrumented with vertical and horizontal strain gauges to measure Poisson's ratio. The prism had dimensions of $43 \times 43 \times 85 \mathrm{~mm}$, similar to the acrylic sample described above (but without the holes). This exercise gave $E=3250$ $\mathrm{MPa}$ and $v=0.38 . C_{\mathrm{g}}$ was then calculated as $1 / K$, where $K$ is the bulk modulus $=[E /(3(1-2 v)]$, and found to be $2.2 \times 10^{-7} \mathrm{kPa}^{-1}$. 


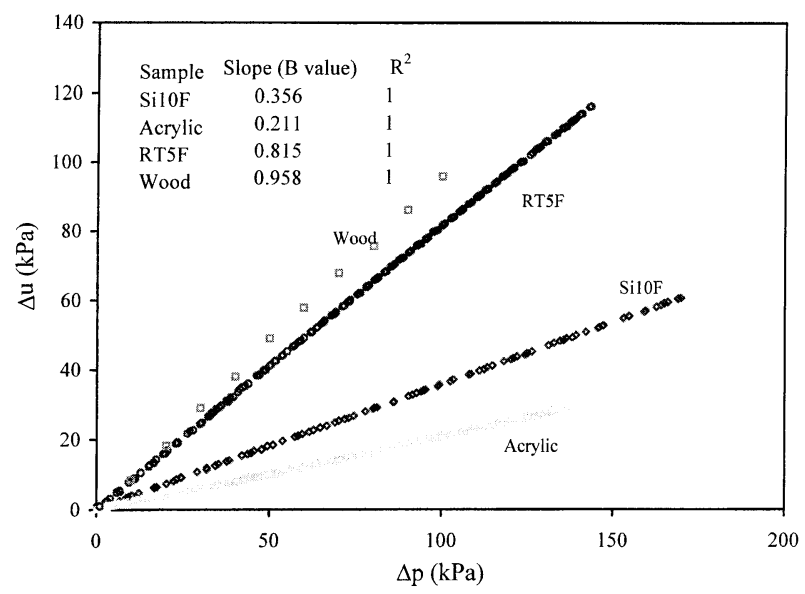

Fig. 12. Variation of $(\Delta u / \Delta q)$ with the direction of TSP in undrained shear test

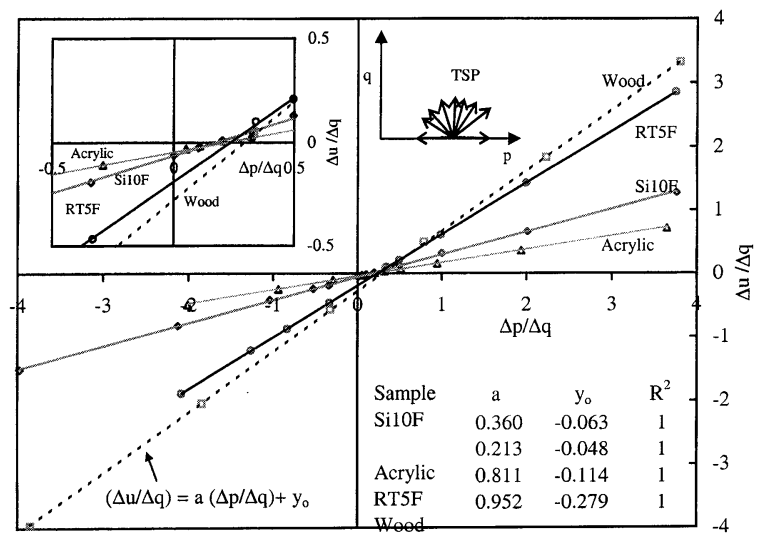

Fig. 13. Grain size distribution curves of $\mathrm{Si}$ and $\mathrm{RT}$ sands before cementation

\section{RESULTS AND ANALYSIS}

The experimental results are summarised in Figs. 12 and 13 in terms of $\Delta u$ versus $\Delta p$ and $(\Delta u / \Delta q)$ versus $(\Delta p / \Delta q)$, respectively. In the following analysis, two main points will be discussed: (a) validation of Eq. (8) and (b) influence of anisotropy and membrane compliance on the pore pressure results.

\section{Validation of Eq. (8) and Possible Existence of Anisotropy}

Scrutiny of Figs. 12 and 13 shows that, for all tested materials, the relationship between $(\Delta u / \Delta q)$ versus $(\Delta p /$ $\Delta q$ ) has reduced to a straight line with a slope very close to the $B$ value measured from the probe $\Delta q=0$ as predicted by Eq. (8). For all samples, the intercept terms have non-zero values, though different in magnitude.

As listed in Fig. 12, except for the Pinewood sample, the measured $B$ values are all much less than unity, reflecting low skeleton compressibility, with $B=0.815$, 0.356 and 0.211 for RT5F, Si10F and Acrylic samples, respectively. The measured $B$ value for the Pinewood
Table 4. Measured versus calculated values of $B$

\begin{tabular}{ccccc}
\hline \multirow{2}{*}{ Sample } & \multirow{2}{*}{$C\left(\mathrm{kPa}^{-1}\right)$} & \multirow{2}{*}{$\begin{array}{c}\text { Porosity } \\
(n)\end{array}$} & & \multicolumn{2}{c}{$B$} \\
\cline { 4 - 5 } & & & Measured & Calc. (Eq. (7)) \\
\hline RT5F & $1.539 \times 10^{-7}$ & 0.385 & 0.815 & 0.412 \\
Si10F & $7.628 \times 10^{-8}$ & 0.236 & 0.356 & 0.308 \\
\hline
\end{tabular}

sample is 0.958 , which is expected for such soft material. Recalling from Eq. (7) that the $B$ value depends on the combined effect of $n, C_{\mathrm{g}}$ and $C$, it may not be surprising that the lowest $B$ value was recorded for the Acrylic sample (see Fig. 11), although its volumetric compressibility is greater than that of RT5F and Si10F samples $\left(C_{\mathrm{g}}\right.$ for acrylic $\left.=2.2 \times 10^{-7} \mathrm{kPa}^{-1}\right)$.

\section{Measured versus Predicted Value of B}

It is interesting now to compare the measured $B$ values with those calculated from Eq. (7) for RT5F and Si10F samples.

For the Si10F sample, the predicted $B$ value using Eq. (7) is 0.308 , which is about $13 \%$ less than the measured one $\left(B_{\text {measured }}=0.356\right.$, Table 4$)$. In the case of RT5F sample, the difference is about $98 \%$ with $B=0.815$ and 0.412 for the measured and calculated values, respectively.

It is believed that the higher measured values of $B$ are attributed to membrane penetration (Eq. (6)). During a $B$ value test on a stiff material, the application of a total pressure increment will shed effective stress onto the skeleton according to the relationship $\Delta \sigma_{3}^{\prime}=\Delta p^{\prime}=(1-$ $B) \Delta p$. The increase in $\sigma_{3}^{\prime}$ will, therefore, cause membrane penetration, which leads to reduction in the total volume of the sample and fictitious increase in the $B$ value. For cemented samples, the magnitude of the membrane penetration depends on the surface condition and how far the cementing agent can fill the peripheral interparticle voids. The gradation curves of $\mathrm{Si}$ and $\mathrm{RT}$ sands before cementation (Fig. 6) indicates their potential to experience membrane-induced volume change as may be inferred from $D_{50}$ or $D_{20}$ (Nicholson et al., 1993). In fact, although 10 and 5 flushes were applied to the silica and RT sands respectively, the micrographs shown in Figs. 14(a) and (b) indicate that after the cementation process, the fabric of both samples has remained open, though more obvious in the case of the RT5F sample. It is believed that the greater influence of the membrane penetration in the case of the RT5F sample is also attributed to the irregular nature of the calcareous grains.

Two approaches can be used to test the influence of membrane penetration on the measured $B$ value. In the first, the membrane flexibility can be measured and substituted for in Eq. (6) to see how it affects the predicted $B$ value. In the second approach, an attempt may be made to reduce the influence of the membrane penetration before testing. Both approaches will be discussed next, for the case of the RT5F sample.

Figure 15 shows the relationship between the volumetric strain $\left(\varepsilon_{v}\right)$ and $\sigma_{3}^{\prime}$ during consolidation of the RT5F 


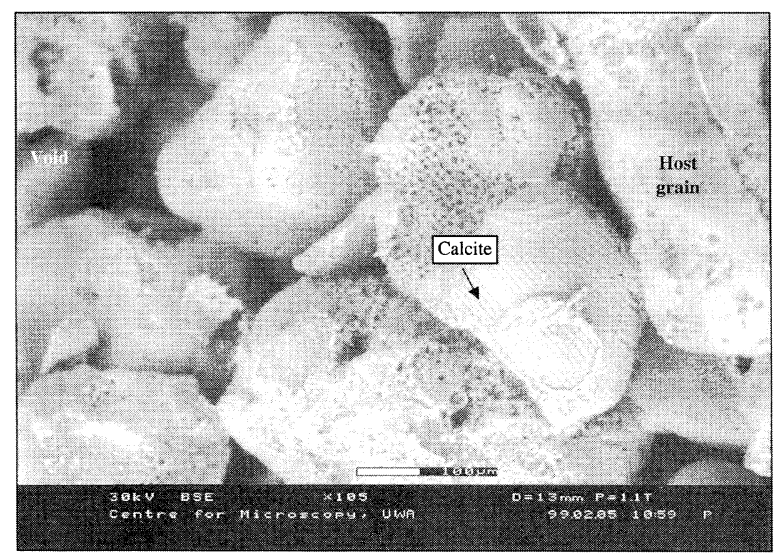

(a) RT5F sample

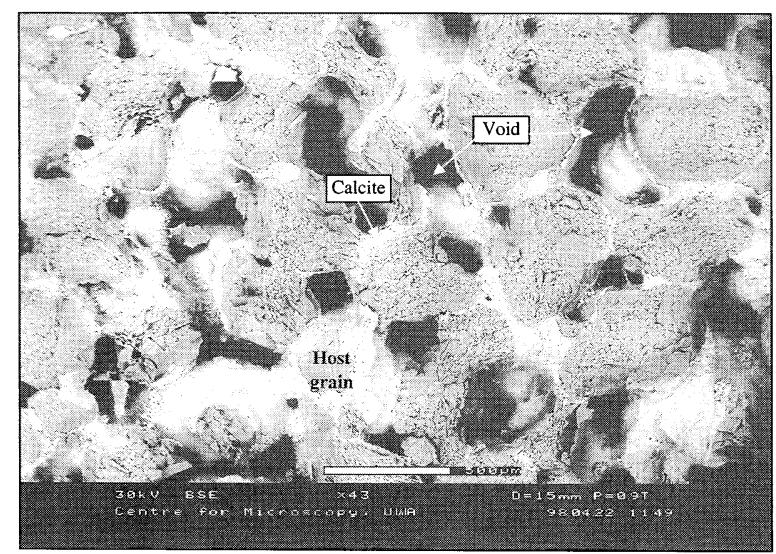

(b) Si10F sample

Fig. 14. Electron microscopy micrographs of Si10F and RT5F samples showing the still open fabric after cementation

sample to $p^{\prime}=800 \mathrm{kPa}$ (curve A). It is interesting to note (inset of Fig. 15) that this relationship is similar to that discussed earlier for uncemented granular materials in Fig. 4. Superimposed on the same plot is Curve B, which represents the actual volumetric response of the skeleton. It should be noted that $\varepsilon_{\mathrm{v}}$ for Curve B was calculated from the relationship $\left(\varepsilon_{\mathrm{v}}=\varepsilon_{1}+2 \varepsilon_{3}\right)$, where both $\varepsilon_{1}$ and $\varepsilon_{3}$ were measured locally using internal LVDTs. Subtracting curve $\mathrm{B}$ from curve $\mathrm{A}$ gives the volumetric strain induced by the membrane penetration (curve D). The membrane flexibility $\left(f_{\mathrm{m}}\right)$ at any lateral stress can then be calculated from the relationship:

$f_{\mathrm{m}}=$ slope $* V_{0}$, which gives $f_{\mathrm{m}}=1.832 \mathrm{~mm}^{3} / \mathrm{kPa}$ at $p^{\prime}=$ $500 \mathrm{kPa}$ for an initial volume $\left(V_{\mathrm{o}}\right)$ of $666515 \mathrm{~mm}^{3}$. If the value of $f_{\mathrm{m}}$ is substituted in Eq. (6), we get $B=0.9$, which is now closer to $B_{\text {measured }}=0.815$.

Following the second approach, a thin layer of latex rubber (Lo et al., 1989) was introduced between the rubber membrane and the surface of the RT5F sample. The sample was then set up in the triaxial apparatus, and a confining stress of $100 \mathrm{kPa}$ was applied for curing overnight. The advantages of using the liquid rubber are (1) it does not increase the stiffness of the tested material, (2) it fills all the interstices on the sample surface and (3) it

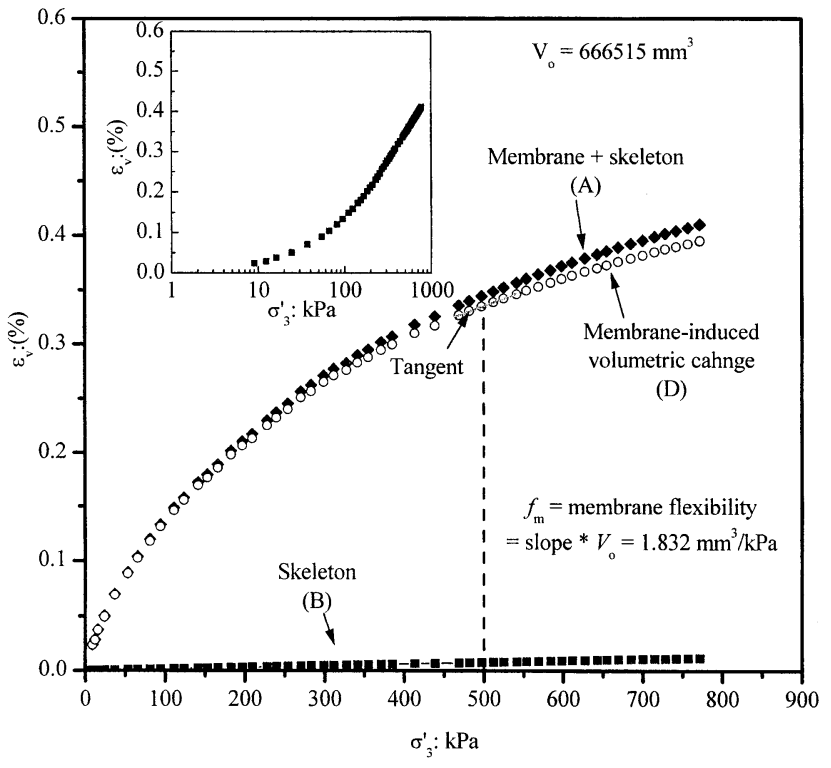

Fig. 15. Calculation of membrane flexibility from consolidation curve for RT5F sample

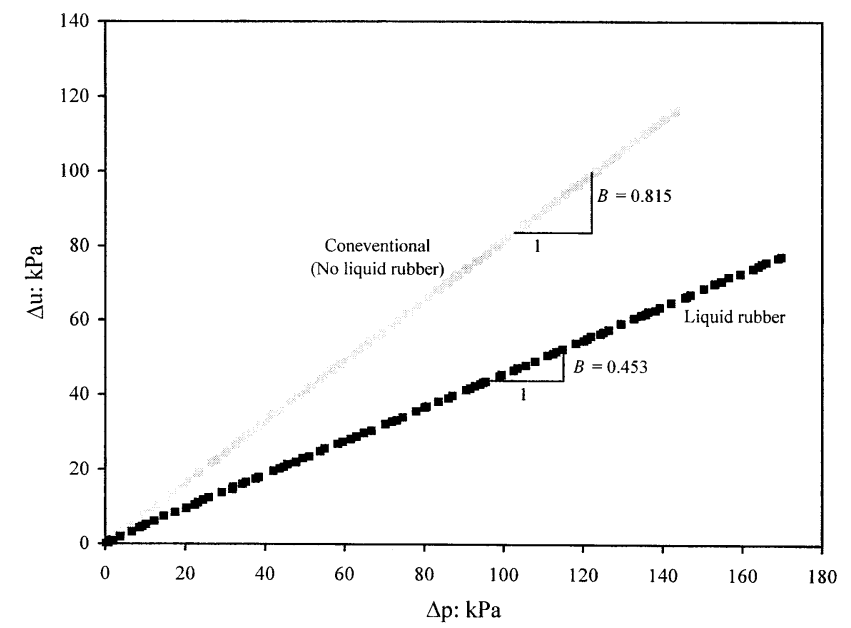

Fig. 16. Reducing the influence of membrane penetration on $B$ value using liquid rubber

has excellent adherence to the outer rubber membrane, so they work as one sheath. The sample was then tested again as described above and the $B$ value was measured. Figure 16 shows a drastic reduction in $B$ from 0.811 to 0.453 , which is now much closer to the value calculated from Eq. (7) as 0.412 .

It turns out from this discussion that the membrane compliance may lead to significant error in the pore pressure during a $B$-value test, and unless eliminated or taken into account, it would mask the true behaviour of the tested material.

\section{True Anisotropy or Membrane-Induced Anisotropy}

When a stiff sample is enclosed in a rubber membrane and the surface condition provides a room for the membrane to deform exclusively with change in lateral 
effective stress, the overall behaviour of the sample will be characterised by a pseudo flexibility in the horizontal direction. This means that under any stress path other than $d \sigma_{3}^{\prime}=0$, an elastic isotropic sample will appear as if it has a higher vertical than horizontal stiffness. This has been spelt out in Eq. (8) through the negative sign of the third term (right-hand side), which represents the influence of the membrane compliance. The negative sign implies that, because of the membrane flexibility, the pore pressure generated during an undrained probe will always be underestimated and, therefore, the ESP will always lean to the right of the true one. The serious implication of this argument is that membrane compliance may be misinterpreted as a degree of intrinsic anisotropy.

The performance of the Pinewood sample provides a relevant example as to how the membrane compliance is qualitatively equivalent to anisotropy of $G_{\mathrm{o}(\mathrm{hh})}<G_{\mathrm{o}(\mathrm{hv})}$. For this sample, $G_{\mathrm{o}(\mathrm{hh})}$ is less than $1 / 15^{\text {th }} G_{\mathrm{o}(\mathrm{hv})}$ (see Table 3 ). Although the sample had a very smooth surface, the membrane compliance was completely removed by gluing the membrane to the sample surface using a very thin layer of Loctite adhesive. Therefore, any intercept would be due to the anisotropy term of Eq. (8). As shown from the results of Fig. 13, the intercept term is the highest among all the samples with a value of -0.279 .

The surface of the Acrylic sample was intrinsically smooth and, therefore, membrane compliance did not have any effect on the results.

\section{FURTHER DISCUSSION}

\section{Quantifying the Membrane-Induced Anisotropy}

It is now interesting to quantify the degree of anisotropy equivalent to the intercept terms obtained from Fig. 13, bearing in mind that in the case of RT5F and Si10F samples, these values represent the membraneinduced anisotropy. To achieve this, the modulus $J$ may be calculated from Eq. (8) as a function of the intercept. The ratio between $G_{\mathrm{o}(\mathrm{hh})}$ and $G_{\mathrm{o}(\mathrm{hv})}$ can then be determined from the relationship between $J$ and the other elastic parameters. From Eq. (8), $J$ can be calculated as

$$
J=\left(\frac{B}{C-C_{\mathrm{g}}}\right)\left(\frac{1}{Y_{\mathrm{o}}}\right)
$$

where $y_{\mathrm{o}}$ is the intercept obtained from Fig. 13. Table 5 provides the values of $J$ calculated for RT5F, Si10F, and Acrylic samples (the intercept $Y_{\mathrm{o}}$ is taken from Fig. 13). The relationship between $J$ and the other elastic parameters for an anisotropic material can be written as (Lings et al., 2000)

$$
J=\frac{3}{2\left[\frac{1-v_{\mathrm{vh}}}{E_{\mathrm{v}}}-\frac{1-v_{\mathrm{hh}}}{E_{\mathrm{h}}}\right]}
$$

Rearrangement of Eq. (11) will lead to:

$$
E_{\mathrm{h}}\left(1-v_{\mathrm{vh}}\right)-E_{\mathrm{v}}\left(1-v_{\mathrm{hh}}\right)=\frac{3}{2 J} E_{\mathrm{v}} E_{\mathrm{h}}
$$

Table 5. Predicted versus measured degree of stiffness anisotropy

\begin{tabular}{lcccc}
\hline Sample & $\begin{array}{c}\text { Intercept } \\
\left(y_{\mathrm{o}}\right)\end{array}$ & $J(\mathrm{MPa})$ & $\begin{array}{c}E_{\mathrm{h}} / E_{\mathrm{v}} \\
\text { (predicted) }\end{array}$ & $\begin{array}{c}E_{\mathrm{h}} / E_{\mathrm{v}} \\
\text { (measured) }\end{array}$ \\
\hline RT5F & -0.114 & -290037 & 0.620 & 0.953 \\
Si10F & -0.063 & -105397 & 0.670 & 1.006 \\
Acrylic & -0.048 & -84639 & 0.961 & 0.981 \\
\hline
\end{tabular}

Table 6. Theoretical $B$ values for RT samples with different levels of cementation

\begin{tabular}{ccccc}
\hline Sample & RT1F & RT2F & RT3F & RT5F \\
\hline$B$ & 0.836 & 0.671 & 0.597 & 0.412 \\
\hline
\end{tabular}

But $\alpha^{2}=E_{\mathrm{h}} / E_{\mathrm{v}}$ (by definition), hence Eq. (10) can be rewritten, after rearrangement, as

$$
\alpha^{2}=\frac{1}{\left(\frac{1-v_{\mathrm{vh}}}{1-v_{\mathrm{hh}}}\right)-\left(\frac{3 G_{\mathrm{hv}}\left(1+v_{\mathrm{vh}}\right)}{J\left(1-v_{\mathrm{hh}}\right)}\right)}
$$

In the case of isotropic materials (note that $J$ is a consequence of membrane penetration), Eq. (12) reduces to

$$
\alpha^{2}=\frac{1}{1-\left(\frac{3 G_{\mathrm{hv}}(1+v)}{4 J(1-v)}\right)}
$$

Substituting $J, v_{\mathrm{vh}}, v_{\mathrm{hh}}$ and $G_{\mathrm{hv}}$ into Eq. (13) yields the values of $\alpha^{2}$ presented in Table 5, which indicates significant degree of anisotropy in the case of RT5F and Sil0F samples. (The values of $v_{\mathrm{vh}}, v_{\mathrm{hh}}$ and $G_{\mathrm{hv}}$ are taken from Table 3 and $J$ is taken from Table 5).

The implication of this membrane-induced anisotropy will now be examined for cemented RT samples in a conventional CIU test. In this test, the sample was consolidated isotropically to an effective pressure of $500 \mathrm{kPa}$ before being sheared undrained within the elastic range. Figure 16 shows the measured change in $(\Delta u / \Delta q)$ with skeleton compressibility for samples of different levels of cementation $(1,2,3$ and 5 flushes of the CIPS solution). Superimposed on the same figure is the corrected pore pressure ratio $(\Delta u / \Delta q)$, with correction for the membrane compliance. The corrected values are calculated from the following relationships, where $B$ (listed in Table 6) is determined from Eq. (7):

$$
\begin{aligned}
& \Delta u=B \Delta p=B \frac{\Delta q}{3} \quad \text { (for constant cell pressure) } \\
& \frac{\Delta u}{\Delta q}=\frac{B}{3}
\end{aligned}
$$

The results in Fig. 17 demonstrate substantial error in the measured pore pressure because of the membrane compliance, which has led to pore pressure values of only $20 \%$ of the true values.

\section{CONCLUDING REMARKS}

This paper has presented the results of a study on the influence of skeleton stiffness, membrane compliance and 


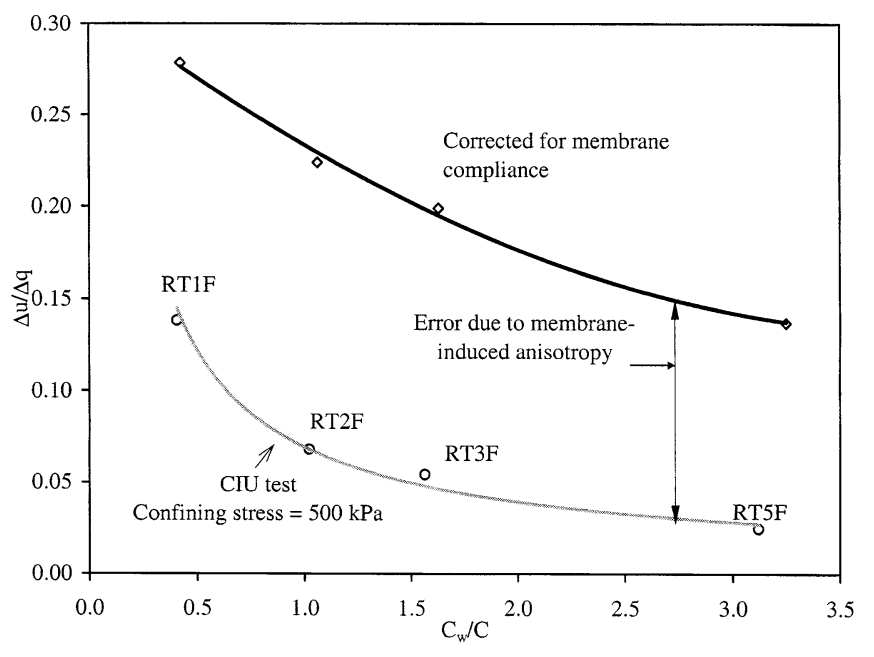

Fig. 17. Variation of $(\Delta u / \Delta q)$ with compressibility of the skeleton for cemented samples of RT sand in CIU test

intrinsic anisotropy on pore pressure response of materials of different origin during elastic loading. Based on the experimental finding and analysis of the results, the following points may be concluded.

1) A pseudo degree of anisotropy may develop because of membrane compliance, and unless eliminated or accounted for, it could lead to misinterpretation of pore pressure response.

2) Complete separation should be made between the influence of volumetric stiffness, true anisotropy and membrane-induced anisotropy on experimental results before interpreting pore pressure response during undrained loading.

3) Experimental results have shown that plotting the pore pressure gradient $(\Delta u / \Delta q)$ versus the direction of the TSP $(\Delta p / \Delta q)$ is a suitable means to identify any degree of anisotropy. For an elastic material, this plot should give a straight line with a slope $B$ and intercept representing the degree of anisotropy. The equality of the slope to $B$ may be considered as another means to verify full saturation of the sample.

4) Intrinsic or membrane-induced anisotropy can be quantified approximately using simple procedures based on Eq. (8) and a relationship between elastic parameters.

5) Any of the elastic parameters should not be determined from the volume change (in a drained test) measured via a volume change transducer, as long as membrane penetration is likely to occur. In such case, the volume change should be calculated from axial and radial strains measured locally on a triaxial sample.

\section{ACKNOWLEDGEMENTS}

The work presented in this paper forms part of the activities of the Centre for Offshore Foundation Systems (COFS), established and supported under the Australian Research Council's Research Centres Program.

\section{NOTATION}

$A$ : Skempton pore pressure parameter

$A^{*}: \Delta u / \Delta q$ during an undrained loading

$\alpha^{2}: \quad E_{\mathrm{h}} / E_{\mathrm{v}}$

$B$ : Skempton pore pressure parameter

$C$ : Compressibility of soil skeleton

$C_{\mathrm{g}}$ : Compressibility of soil grains

CIU: Isotropically consolidate undrained triaxial test

$C_{\mathrm{w}}$ : Compressibility of water

$d \varepsilon_{\mathrm{q}}$ : Elastic deviator strain

$d \varepsilon_{\mathrm{v}}:$ Elastic volumetric strain

$E_{\mathrm{h}}, E_{\mathrm{v}}$ : Horizontal and vertical Young's modulus

ESP: Effective stress path

$f_{\mathrm{m}}$ : Membrane flexibility

$G$ : Elastic shear modulus

$G_{\mathrm{hh}}, G_{\mathrm{hv}}$ : Shear moduli along horizontal and vertical plane, respectively

$J$ : Modulus coupling shear stress and elastic volumetric strain

$K$ : Bulk modulus

$n$ : Porosity

$q$ : Deviator stress

TSP: Total stress path

$V_{\mathrm{o}}$ : Initial volume

$\Delta p:$ Total stress increment

$\Delta q$ : Deviator stress increment

$\delta v_{\mathrm{m}}$ : Unit membrane compliance

$\varepsilon_{1}, \varepsilon_{3}$ : Major and minor principal strains

$\sigma_{1}^{\prime}, \sigma_{3}^{\prime}$ : Major and minor principal effective stress

\section{REFERENCES}

1) Atkinson, J. H. (1975): Anisotropic elastic deformations in laboratory tests on undisturbed London Clay, Géotechnique, 25(2), 35-374.

2) Atkinson, J. H. and Sällfors, G. (1991): Experimental determination of stress-strain-time characteristics in laboratory and in situ tests, General Report, Proc. 10th Eur. Conf. on SMFE, Florence, 3, 915-956.

3) Baldi, G. and Nova, R. (1984): Membrane penetration effects in triaxial testing, J. Geotech. Engrg. Div., ASCE, 110(3), 403-419.

4) Bishop, A. W. (1973): The influence of an undrained change in stress on the pore pressure in porous media of low compressibility, Géotechnique, 23(3), 435-441.

5) Bridgman, P. W. (1925): The linear compressibility of 14 natural crystals, Am. J. Sci., 10, 483-498.

6) Cuccovillo, T. and Coop, M. R. (1998): Characterising the elastic response of very stiff coarse grained soils, Proc. Int. Symp. Geotech. Engrg. Hard Soils-Soft Rocks, Naples, 1, 491-496.

7) Frydman, S., Zeitlen, J. G. and Alpan, I. (1973): The membrane effect in triaxial testing of granular soils, J. Test. Eval., 1(1), 37-41.

8) Graham, J. and Houlsby, G. T. (1983): Anisotropic elasticity of a natural clay, Géotechnique, 33(2), 165-180.

9) Graham, J. and Shields, D. H. (1985): Influence of geology and geological processes on the geotechnical properties of a plastic clay, Engrg. Geol., 22, 109-126.

10) Hight, D. W. (1982): A simple piezometer probe for the routine measurement of pore pressure in triaxial tests on saturated soils, Géotechnique, 32(2), 396-401.

11) Ismail, M. A., Joer, H. A. and Randolph, M. F. (2000): Sample preparation technique for artificially cemented soils, ASTM Geotech. Test. J., 23(2), 171-177.

12) Ismail, M. A., Joer, H. A., Randolph, M. F. and Meritt, A. (2002): Cementation of porous materials using calcite precipitation, Géotechnique, 52(5), 313-324.

13) Ismail, M. A., Sharma, S. S. and Fahey, M. (2005): True triaxial apparatus with wave velocity measurement, Geotech. Test. J., GTJODJ, 28 (2), 113-122.

14) Lade, P. V. and Hernandez, S. B. (1977): Membrane penetration effects in undrained tests, J. Geotech. Engrg. Div. ASCE, 
103(GT2), 109-125.

15) Lings, M. L., Pennington, D. S. and Nash, D. F. T. (2000): Anisotropic stiffness parameters and their measurement in a stiff natural clay, Géotechnique, 50(2), 109-125.

16) Lo, S-C., Chu, J. and Lee, I. K. (1989): Technique for reducing membrane penetration and bedding errors, ASTM Geotech. Test. J., 12(4), 311-316.

17) Nicholson, P. G., Seed, R. B. and Anwar, H. A. (1993): Elimination of membrane compliance in undrained triaxial testing: measurement and evaluation, Can. Geotech. J., 30, 727-738.

18) Peyton, F. A. and Craig, R. G. (1963): Current evaluation of plastics in crown and bridge prosthesis, J. Prosthet. Dent., 13(4), $743-753$.
19) Raju, V. S. and Sadasivan, S. K. (1974): Membrane penetration in triaxial tests on sands, J. Geotech. Engrg. Div., ASCE, 100(4), 482-489.

20) Sivathayalan, S. and Vaid, P. Y. (1998): Truly undrained response of granular soils with no membrane-penetration effects, Can. Geotech. J., 35, 730-739.

21) Skempton, A. W. (1954): The pore-pressure coefficients A and B, Géotechnique, 4(1), 143-147.

22) Wissa, A. E. (1969): Pore pressure measurement in saturated stiff soil, J. Geotech. Engrg. Div., ASCE, 95(SM4), 1063-1073.

23) Zimmerman, R. W. (1991): Compressibility of Sandstones, Elsevier. 